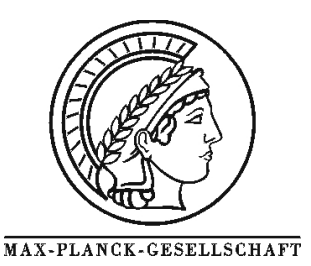

Physical Review B, 67 (2003), 1-12

\title{
The Nature of Atomic Oxygen Species on Silver: photoelectron spectroscopy and X-ray absorption studies
}

\author{
V.I. Bukhtiyarov ${ }^{1}$, M. Hävecker ${ }^{2}$, V.V. Kaichev ${ }^{1}$, A. Knop-Gericke ${ }^{2}$, R.W. Mayer $^{2}$ and R. Schlögl ${ }^{2}$ \\ ${ }^{1}$ Boreskov Institute of Catalysis, Lavrentieva prosp. 5, 630090, Novosibirsk, Russia
}

${ }^{2}$ Department of Inorganic Chemistry, Fritz-Haber-Institute of the MPG, Faradayweg 4-6, 14195 Berlin, Germany

${ }^{*}$ Corresponding author: e-mail XYZ, phone +49 308413 3192, fax +49 3084134401

Received 09 April 2002; published 27 June 2003

\begin{abstract}
Two oxygen species, which are constituents of the active centers for ethylene epoxidation over silver, have been characterized by a number of physical methods sensitive to adsorbate electronic structure such as XPS, UPS, Auger and XANES spectroscopy. One of the species denoted as nucleophilic oxygen due to its activity in total oxidation only exhibits spectroscopic characteristics close to those of bulk $\mathrm{Ag}_{2} \mathrm{O}$. This allows us to describe this species as atomically adsorbed oxygen in the structure of surface silver (I) oxide. Considerable extent of the covalency in bonding of this oxide-like oxygen with silver surface due to hybridization of O2p levels with Ag4d and Ag5sp orbitals should be also emphasized. Contrary to this only $5 \mathrm{sp}$ orbitals of silver hybridize with 2 p levels of oxygen as the other oxygen species forms. As consequence, this species being also atomic oxygen is characterized by a lower oxygen-silver bonding interaction and lower charge on the oxygen. The latter causes the activity of this electrophilic species in epoxidation. Possible models of adsorption centers for these oxygen species are discussed.
\end{abstract}

\section{Introduction}

The well-known activity of silver as catalysts for selective oxidation of a number of hydrocarbons (not only ethylene [1-4] or methanol [5], but also styrene [6] and methane [7]) has generated during the last thirty years a huge number of investigations devoted to the interaction of oxygen with silver surfaces (see for example [4,8-17]). Surface science identified various oxygen species adsorbed on silver. It has been shown that at low temperatures oxygen adsorbs molecularly [11-15]. Heating causes dissociation of $\mathrm{O}_{2, \text { ads }}$ and/or its desorption at $170-220 \mathrm{~K}$, with both the temperature and the route of transformation being dependent on the surface structure of silver. Atomic oxygen is stable up to $600 \mathrm{~K}$ when its associative desorption takes place [8-17]. Furthermore, at $\mathrm{T} \geq 420 \mathrm{~K}$ surface oxygen atoms can dissolve into the silver bulk [10-11]. This scheme of oxygen states and their mutual transformations has been summarized in a comprenhensive review [4].
At the same time, there are many experimental results which indicate that the above-mentioned picture of oxygen states is oversimplified and that it would be more correct to identify three classes of states, each of which includes few species with various electronic properties. For instance, Campbell et al have shown that both peroxide [13] and superoxide [14-15] states of $\mathrm{O}_{2 \text {,ads }}$ are formed on the surfaces of silver single crystals. In the papers of van Santen et al it has been revealed experimentally [3,4] and theoretically [18] that dissolved oxygen located in subsurface silver layers switches over the routes of ethylene oxidation from total oxidation to $\mathrm{CO}_{2}$ and $\mathrm{H}_{2} \mathrm{O}$ production to ethylene epoxidation. The authors suggested that a variation of the electronic structure of atomically adsorbed oxygen is responsible for this selectivity switch [18].

Our previous papers concluded the formation of several adsorbed oxygen species under in-situ reaction conditions [19-23]. The identification of various oxygen species was achieved using X-ray photoelectron spectroscopy (XPS) 
and temperature programmed desorption (TPD). One of these species that appeared as the result of high temperature and atmospheric pressure treatment of clean silver by $\mathrm{O}_{2}$ has been characterized by an O1s binding energy of $529.0 \pm 0.2$ $\mathrm{eV}$ [19-20]. Following traditional TPD nomenclature this oxygen has been denoted as $\mathrm{O}_{\gamma}$ because of its higher desorption temperature $(\sim 850 \mathrm{~K})$ compared to those of surface adsorbed $\left(\mathrm{T}_{\mathrm{des}} \sim 600 \mathrm{~K}\right)$ and bulk dissolved $\left(\mathrm{T}_{\mathrm{des}} \sim 650-750\right.$ $\mathrm{K}$ ) oxygen denoted as $\mathrm{O}_{\alpha}$ and $\mathrm{O}_{\beta}$, respectively. It has been shown that $\mathrm{O}_{\gamma}$ participates into the selective oxidation of methanol to formaldehyde [19-20] and oxidative coupling of methane [7]. The detailed study of the $\mathrm{O}_{\gamma}$ carried out using X-ray and ultraviolet photoelectron spectroscopy (XPS and UPS), ion scattering spectroscopy (ISS), X-ray absorption near edge structure (XANES) spectroscopy [19-20] has shown that this species represents strongly bound atomic oxygen embedded in the top atomic layer of silver. Such a structure allowed the authors to describe this oxygen as Lewis base that is in accordance with its activity in elimination of hydrogen atoms from methanol.

Two other species have been reported in the papers devoted to ethylene epoxidation over silver [21-23]. One of these oxygen species has been characterized by an O1s binding energy of $528.3 \pm 0.2 \mathrm{eV}$ and the second one of $530.5 \pm 0.2 \mathrm{eV}$. To clarify their role in ethylene epoxidation we have monitored the isotopic composition of products during temperature programmed reaction (TPR) of ethylene coadsorbed with the isotopically-labelled $\mathrm{O}_{\text {ads }}$ [22]. The TPR spectroscopy data allowed to show that the former oxygen is active in nucleophilic attack of $\mathrm{C}-\mathrm{H}$ bond (the first step of total oxidation of ethylene [24]), while the latter one - in electrophilic addition to double $\mathrm{C}=\mathrm{C}$ bond. So, following to the paper of Grant and Lambert [2], these species have been denoted as the nucleophilic $\left(\mathrm{E}_{\mathrm{b}}(\mathrm{O} 1 \mathrm{~s})=528.3 \mathrm{eV}\right)$ and electrophilic $\left(\mathrm{E}_{\mathrm{b}}(\mathrm{O} 1 \mathrm{~s})=530.5 \mathrm{eV}\right)$ oxygen. The same classification will be used in this paper.

If the nucleophilic oxygen has been observed in many papers and, as consequence, has been studied in more detail, so the nature of the electrophilic oxygen has not been clarified yet. It is evident that elucidation of reasons which cause so considerable variation (up to $2 \mathrm{eV}$ ) in O1s binding energy should be a first steps in this direction. All oxygen species should be characterized using a complmentary combination of physical methods, with special attention being paid to the selection of the conditions of formation of the individual species and to their stability during spectroscopic characterization.

In this paper we present the results of a combined photoelectron spectroscopy and X-ray absorption study for the nucleophilic and electrophilic oxygen. We used our previous data [21-23] in order to select the conditions of individual preparation of these oxygen species. As shown in this paper also, the nucleophilic oxygen is prepared by adsorption of pure oxygen, whereas the electrophilic one is effectively produced if a clean silver is treated by $\mathrm{C}_{2} \mathrm{H}_{4}+\mathrm{O}_{2}$ reaction mixtures. Selective formation of these species al- lowed us to make the assignment of the observed spectroscopic features more thoroughly.

\section{Experimental}

The photoemission part of this investigation was carried out using a VG ESCALAB HP electron spectrometer with the base pressure $<5 \times 10^{-10}$ mbar. Differential pumping of energy analyzer and X-ray tube by diffusion pumps [25-26] makes it possible to measure photoemission spectra in-situ directly in analyzer chamber at pressures up to $10^{-4}$ mbar. Insertion of the special gas cell into the analyzer chamber allows increase in the pressure of in-situ measurements up to 0.1-0.2 mbar but decreases XPS intensity. The treatment at higher pressures (up to $1 \mathrm{~atm}$ ) could be realized in the preparation chamber. Subsequent evacuation to UHV followed by transportation of the sample to the analyzer chamber takes about 5 min, afterwards ex-situ monitoring of photoemission spectra can be started. X-ray photoelectron and X-ray induced Auger electron spectra were taken using $\mathrm{MgK} \alpha$ irradiation $(\mathrm{hv}=1253.6 \mathrm{eV})$ and calibrated against $E_{b}\left(\mathrm{Ag} 3 \mathrm{~d}_{5 / 2}\right)$ $=368.2 \mathrm{eV}$ measured for clean metallic silver. UPS spectra were measured using HeI irradiation $(\mathrm{hv}=21.2 \mathrm{eV})$ and calibrated against the Fermi level.

The photon-energy-dependent X-ray absorption spectroscopy measurement were performed at the HETGM1 beamline of the Berliner Synchrotron Radiation source BESSY-I with an electron beam energy of $0.8 \mathrm{GeV}$. A toroidal grating monochromator equipped with two gratings (1100 lines $/ \mathrm{mm}$ and 1500 lines $/ \mathrm{mm}$ ) was used; it is operated at a resolution of $1.8 \mathrm{eV}$ at the $\mathrm{O} K$-edge. XAS spectrometer attached to BESSY consisted of a doublechamber UHV system with a base pressure of $<5 \times 10^{-9}$ mbar. Both the construction of XAS spectrometer and procedure of XAS spectra measurement have been described in detail elsewhere [27]. In short, the spectra were collected with the 1100 lines $/ \mathrm{mm}$ grating in the photon energy range of $250 \mathrm{eV} \leq \mathrm{hv} \leq 1000 \mathrm{eV}$. C $K$-edge and $\mathrm{O} K$-edge spectra have been accumulated with total electron yield detection using an accelerating voltage of $+4.5 \mathrm{~V}$. O $K$-edge spectra were calibrated using XAS signal of the gas phase oxygen at $530.8 \mathrm{eV}$ recorded at $\mathrm{O}_{2}$ pressure of $10^{-1} \mathrm{mbar}$.

The same polycrystalline foil of silver (Goodfellow, 99.95\%) was used as sample for XAS and photoemission measurements. For both types of experiments, the sample was cleaned by the standard high vacuum cycle: $\mathrm{Ar}^{+}$ sputtering, annealing in 10 mbar of $\mathrm{O}_{2}$ at $570 \mathrm{~K}$ and flashing up to $800 \mathrm{~K}$ in UHV. More than ten repetitions of this procedure were necessary to exclude observation of any impurities in the XPS spectra and to obtain invariable XAS spectra of C $K$-edge and $\mathrm{O} K$-edge. For XAS measurements the specimen were mounted to an aluminium nitride plate (electrically insulating but thermally conducting) with a thickness of $\sim 1.5 \mathrm{~mm}$ and an area of $25 \times 25 \mathrm{~mm}^{2}$ (Hoechst AG) by two nickel clips. The aluminium nitride plate was attached to a boron nitride plate ( $\sim 4 \mathrm{~mm}$, Goodfellow). A resistively heated graphite plate covered with boron nitride and mounted between the AlN and BN plates was used to heat 
the sample. The sample temperature was measured by means of alumel - chromel thermocouple attached directly at the back of the sample. In the case of XPS experiments, the sample was fixed on a standard holder which contained a resistive heating element and alumel - chromel thermocouple for temperature control.

\section{Results}

To measure individual spectral characteristics of the oxygen species, two different sets of experiments were carried out. In a first set, photoelectron and X-ray absorption spectra were monitored in-situ at $\mathrm{P}\left(\mathrm{O}_{2}\right)=10^{-4}$ mbar and $\mathrm{T}=$ $470 \mathrm{~K}$. The experiments of the second set included the pretreatment of a clean silver by $\mathrm{C}_{2} \mathrm{H}_{4}(5 \%)+\mathrm{O}_{2}$ reaction mixture for $2 \mathrm{hrs}$ at $\mathrm{P}=1 \mathrm{mbar}$ and $\mathrm{T}=470 \mathrm{~K}$ followed by evacuation and ex-situ monitoring of the corresponding spectra. These conditions have been selected on the basis of literature data $[1-3,10-14]$ and own preliminary experiments [17,21-23]. The adsorption of pure $\mathrm{O}_{2}$ on a clean silver surface produces effectively the nucleophilic oxygen, whereas the electrophilic oxygen accumulates in measurable amounts during the treatment of a silver by mixture of $\mathrm{O}_{2}$ with a ethylene at $\mathrm{P} \geq 1 \mathrm{mbar}$.

Special measures were also taken to avoid the appearance of other oxygen-containing species, the spectral characteristics of which could mask those of the adsorbed oxygen. To avoid the modification of subsurface silver layers by incorporation from the reaction mixture [23], the lowest possible pressure (1 mbar) and small content of ethylene $(2.5 \%)$ in the reaction mixture were applied for generating the electrophilic oxygen. Temperature of the experiments $(470 \mathrm{~K})$ was chosen such as to provide stability of the adsorbed oxygen $\left(\mathrm{T}_{\mathrm{des}}>500 \mathrm{~K}\right.$ [10-14,21-23]), and to prevent the formation of surface carbonates $\left(\mathrm{T}_{\text {decomp }}=420\right.$ $450 \mathrm{~K}$ [11-13]). It should be also noted that the possibility of in-situ measurements at $P\left(\mathrm{O}_{2}\right)=10^{-4}$ mbar is of importance since it allowed us to maintain the saturation coverage $(\Theta=$ 0.5 ) of the highly active nucleophilic oxygen in the steady state regime, when its removal due to oxidation processes with ethylene and unavoidable gas phase impurities was compensated by $\mathrm{O}_{2}$ adsorption from the gas phase.

\section{XPS data}

Figure 1 presents $\mathrm{O} 1 \mathrm{~s}$ and $\mathrm{Ag} 3 \mathrm{~d}$ core level spectra from polycrystalline silver recorded during $\mathrm{O}_{2}$ adsorption (1) and after $\mathrm{C}_{2} \mathrm{H}_{4}+\mathrm{O}_{2}$ reaction mixture treatment (2). The spectra from the clean silver are also shown for comparison. One can see that the clean surface is characterized by the complete absence of any intensity in the $\mathrm{O} 1 \mathrm{~s}$ spectrum indicating that the amount of the residual oxygen that has been observed in many previous papers [21-22,28-29] is below than XPS sensitivity level. The 'clean' Ag3d spectrum exhibits features which can be assigned to the $\mathrm{Ag} 3 \mathrm{~d}_{5 / 2} / \mathrm{Ag} 3 \mathrm{~d}_{3 / 2}$ doublet $(368.2 \mathrm{eV} / 374.2 \mathrm{eV})$ originating from spin-orbit splitting, to the $\mathrm{Ag} 3 \mathrm{~d}_{3 / 2}$ component (A) excited by $\mathrm{MgK \alpha}_{4}$ satellite irradiation line $(\Delta \mathrm{hv}=9.8 \mathrm{eV})$ and to the $\mathrm{Ag} 3 \mathrm{~d}_{3 / 2}$ component (B) excited by $\operatorname{MgK}_{3}(\Delta \mathrm{hv}=8.4 \mathrm{eV})$, respectively, and to the contribution from a plasmon $(\mathrm{C})$ character- istic of metallic silver. All these components are easily seen as result of deconvolution of the total $\mathrm{Ag} 3 \mathrm{~d}$ spectrum as separate components provided that the values of spin-orbital splitting $(6.00 \mathrm{eV})$ and full width at half maximum $(\mathrm{fwhm}=$ $1.1 \mathrm{eV}$ ) of the lines are fixed. This deconvolution made using FitXPS program [30] is presented in the same fig. $1 \mathrm{~b}$.
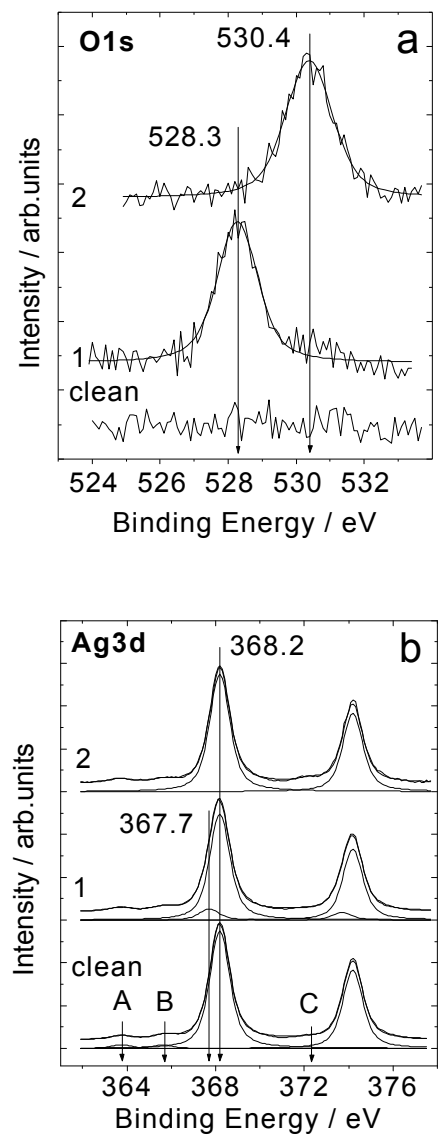

Fig.1. O1s (a) and Ag3d (b) core level spectra from polycrystalline silver foil measured during $\mathrm{O}_{2}$ adsorption at $P=$ $10^{-4}$ mbar and $T=470 \mathrm{~K}(\mathbf{1})$ and after interaction with $\mathrm{C}_{2} \mathrm{H}_{4}$ $+\mathrm{O}_{2}$ reaction mixture for 1 hour at partial pressures of $P\left(\mathrm{C}_{2} \mathrm{H}_{4}\right)=5 \times 10^{-2}$ mbar and $P\left(\mathrm{O}_{2}\right)=2 \mathrm{mbar}$, and $\mathrm{T}=470 \mathrm{~K}$ (2). The spectra from the clean silver are also shown for comparison.

Oxygen adsorption gives rise to a single $\mathrm{O} 1 \mathrm{~s}$ feature at $528.3 \pm 0.1 \mathrm{eV}$ (fig.1a, curve 1). This binding energy value has been reported in many papers [12-14,21-23] and indicates the formation of the nucleophilic oxygen. Its appearance is accompanied by broadening of $\mathrm{Ag} 3 \mathrm{~d}$ peaks (fig.1b) due to the appearance of additional components. Note, although all components of the Ag3d spectrum appeared as result of non-monochromated X-ray irradiation (see the Ag3d spectrum from the clean surface) have taken into account for the deconvolution, only those components, which have been excited by the main $M g K \alpha_{1,2}$ irradiation line, are shown in the figure. The binding energy splitting and the relative intensities of the oxygen-induced lines allow to attribute them to an $\mathrm{Ag} 3 \mathrm{~d}_{5 / 2} / \mathrm{Ag} 3 \mathrm{~d}_{3 / 2}$ doublet (367.7 
$\mathrm{eV} / 373.7 \mathrm{eV}$ ) that is lower in binding energy by $0.5 \mathrm{eV}$ compared to metallic silver.

A different $\mathrm{O} 1 \mathrm{~s}$ feature at $530.4 \pm 0.1 \mathrm{eV}$ appears when the clean silver is treated by $\mathrm{C}_{2} \mathrm{H}_{4}+\mathrm{O}_{2}$ reaction mixture (fig.1a, curve 2). Deconvolution of the corresponding $\operatorname{Ag} 3 d_{5 / 2}$ spectrum (fig.1b, curve 2) shows that the appearance of this O1s line is not accompanied by changes of the 'clean' Ag3d spectrum.

Unfortunately, the binding energy of the new $\mathrm{O} 1 \mathrm{~s}$ line is not so informative as in the case of the nucleophilic oxygen, since not only adsorbed oxygen, but also surface hydroxyls [31-32] or carbonates [12-13,26] could be responsible for this XPS signal. However, its stability at $\mathrm{T}=470 \mathrm{~K}$ in UHV (conditions of the spectrum monitoring) seems to suggest that other surface complexes, than adsorbed oxygen can be excluded. Indeed, both $\mathrm{OH}_{\text {ads }}$ and $\mathrm{CO}_{3 \text {,ads }}$ should desorb at lower temperatures of $360 \mathrm{~K}$ and $450 \mathrm{~K}$, respectively. Most probably, the signal arises from the electrophilic oxygen, which is well-known to be produced effectively at these reaction conditions [21-23]. The assignment of this O1s feature to the adsorbed oxygen, but not to carbonates or hydroxides is also confirmed by $\mathrm{C} 1 \mathrm{~s}$ data showing the absence of the carbonate-derived feature at $~$ $287.5 \mathrm{eV}$ and by UPS (see below).

The data of this part of work demonstrate that the conditions chosen for the oxygen species formation and the in-situ spectra monitoring allow for individual formation and detection of the nucleophilic and electrophilic oxygen. Indeed, full widths at half maximum (fwhm) of the features in the $\mathrm{O} 1 \mathrm{~s}$ spectra (fig.1a) are rather narrow $(1.2-1.4 \mathrm{eV})$ and their integrated intensity ratio to the Ag3d signal corresponds to a coverage of half a monolayer.

\section{UPS data}

Fig. 2 shows HeI $(\mathrm{hv}=21.22 \mathrm{eV})$ ultraviolet photoelectron spectra (a) from the clean silver surface and from silver surfaces covered by the nucleophilic (1) and electrophilic (2) oxygen, as well as the corresponding difference spectra (b). One can see that the 'clean' UP spectrum consists of the silver peaks at $4-7 \mathrm{eV}$ below the Fermi level originating from the Ag4d band emission [19,26,33-36], and by a threshold near the Fermi level originating mainly from Ag5s emission. Additional intensity in the binding energy range of 2-4 eV can be assigned to satellites of the $\mathrm{Ag} 4 \mathrm{~d}$ lines due to $\mathrm{HeI} \beta(\mathrm{hv}=23.08 \mathrm{eV})$ radiation [36]. This signal being not an indicator of impurities on the clean sample was also observed earlier for clean $\operatorname{Ag}(111)$ [19] and $\operatorname{Ag}(110)$ [34-36].

The adsorption of pure $\mathrm{O}_{2}$ and of the reaction mixture modify the 'clean' UPS spectrum. The high intensity of the Ag4d emissions obscures small adsorbate-induced signals. Difference spectra corrected for adsorbate screening are presented in the fig. $2 \mathrm{~b}$. One can see that additional features appear in two ranges of binding energies: $2-4 \mathrm{eV}$ and 5-6 eV. The features located above the Ag4d band have been reported in many previous papers [19,33-36] and were assigned to O2p-derived states. They exhibit considerable difference in binding energy values for the nucleophilic (
$1.9 \mathrm{eV})$ and electrophilic $(\sim 3.3 \mathrm{eV})$ oxygen. The assignment of the features located inside the $\mathrm{Ag} 4 \mathrm{~d}$ band and even their observation are still under discussion. [33-36].
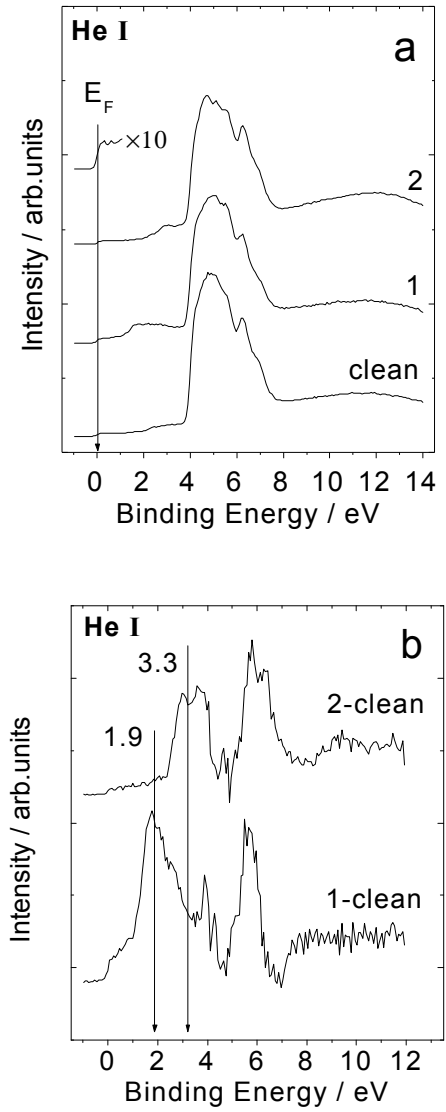

Fig.2. HeI valence band spectra from polycrystalline silver foil measured during $\mathrm{O}_{2}$ adsorption at $P=10^{-4} \mathrm{mbar}$ and $T=$ $470 \mathrm{~K}(1)$ and after interaction with $\mathrm{C}_{2} \mathrm{H}_{4}+\mathrm{O}_{2}$ reaction mixture for 1 hour at partial pressures of $P\left(\mathrm{C}_{2} \mathrm{H}_{4}\right)=5 \times 10^{-2} \mathrm{mbar}$ and $P\left(\mathrm{O}_{2}\right)=2$ mbar, and $\mathrm{T}=470 \mathrm{~K}(2)$. Spectra are presented as is (a) and after subtraction (b) of the spectrum from clean surface also shown for comparison.

However, individual formation of the oxygen species and accurate preparation of the difference spectra show unambiguously their presence in the valence band spectra (fig.2b). In contrast to the signals above the $\mathrm{Ag} 4 \mathrm{~d}$ bands these features exhibit much closer binding energies for the nucleophilic $(\sim 5.7 \mathrm{eV})$ and electrophilic $(\sim 6.0 \mathrm{eV})$ species. It should be also noted that the spectral region for hydroxide and carbonate photoemission (8.2/11.0 eV [34-35] and 8.5 $\mathrm{eV}$ [33], respectively) are free from any features.

\section{Auger data}

Fig. 3 shows $\mathrm{MgK} \alpha$-excited OKLL spectra measured for the nucleophilic (1) and electrophilic (2) oxygen. Our choice of Auger spectroscopy, which nowadays is rarely applied to study adlayers, is explained by its ability to obtain additional information about the electronic structure of the oxygen species. First, the position of the main Auger line is 
used to estimate the contribution of the relaxation effect in the observed shift of binding energies. This approach suggested by Wagner [37-38] has been later modified by Hohlneicher et al [39]. Second, as shown earlier for binary oxides [40-41] the separation and relative intensities of the $\mathrm{OKL}_{23} \mathrm{~L}_{23}$ and $\mathrm{OKL}_{23} \mathrm{~L}_{1}$ lines are indicators of the ionicity of oxygen-metal interaction. A quantitative correlation has been established between the parameters of the OKLL Auger spectra and the formal charge on the oxygen [42]. Finally, it is well-known that X-ray induced Auger spectra are very sensitive to the local electronic structure of oxygen [4345].
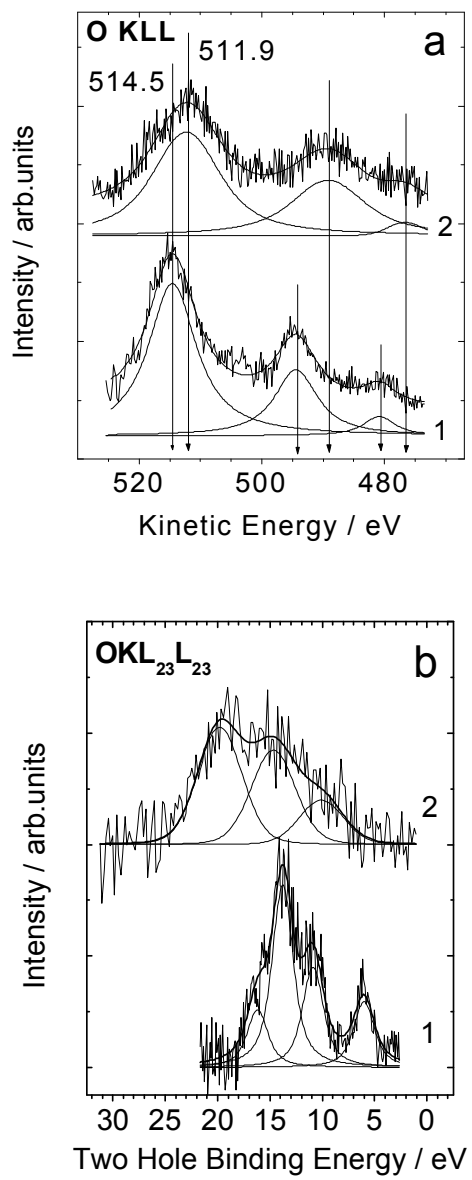

Fig.3. Auger survey OKLL spectra (a) and fine structures of the main $\mathrm{OKL}_{23} \mathrm{~L}_{23}$ line (b) from polycrystalline silver foil measured during $\mathrm{O}_{2}$ adsorption at $P=10^{-4} \mathrm{mbar}$ and $T=470$ $\mathrm{K}$ (1) and after interaction with $\mathrm{C}_{2} \mathrm{H}_{4}+\mathrm{O}_{2}$ reaction mixture for 1 hour at partial pressures of $P\left(\mathrm{C}_{2} \mathrm{H}_{4}\right)=5 \times 10^{-2} \mathrm{mbar}$ and $P\left(\mathrm{O}_{2}\right)=2$ mbar, and $\mathrm{T}=470 \mathrm{~K}(2)$.

The Auger spectra were recorded in two modes: OKLL Auger survey spectra with medium resolution and high sensitivity (fig.3a) and high resolution data of the main $\mathrm{OKL}_{23} \mathrm{~L}_{23}$ line (fig.3b). Since the fine structure of the $\mathrm{OKL}_{23} \mathrm{~L}_{23}$ spectra reflects the valence band structure, the kinetic energy scale of the fig. $3 \mathrm{~b}$ has been translated into a two-hole binding energy scale by subtracting the corresponding O1s core-hole binding energy [45]. One can see that the kinetic energy values of the main $\mathrm{OKL}_{23} \mathrm{~L}_{23}$ line and the splitting between the $\mathrm{OKL}_{23} \mathrm{~L}_{23}$ and $\mathrm{OKL}_{23} \mathrm{~L}_{1}$ ones are quite different for the nucleophilic and electrophilic oxygen species (fig.3a). The measurement of the dominant $\mathrm{OKL}_{23} \mathrm{~L}_{23}$ line with high resolution exhibits the fine structure of the spectra (fig.3b) revealing significant differences in the structure for the nucleophilic and electrophilic oxygen. The spectrum of the former species can be easily approximated by a series of rather narrow lines, whereas the shape of the second spectrum indicates much wider individual contributions as suggested by the deconvolution data. Except for clearly pronounced lower fwhm of the lines, the spectrum of the nucleophilic oxygen exhibits one additional component located closer to the Fermi level $\left(\mathrm{E}_{\mathrm{b}}=6 \mathrm{eV}\right)$.

\section{XANES data}

Like all photoemission spectra, $\mathrm{O} K$-edge absorption spectra from the silver polycrystalline foil were recorded during $\mathrm{O}_{2}$ adsorption and after treatment with $\mathrm{C}_{2} \mathrm{H}_{4}+$ $\mathrm{O}_{2}$ reaction mixture at $\mathrm{T}=470 \mathrm{~K}$. To observe the XAS signals from adsorbed oxygen, the raw spectra were divided by the spectrum of a clean silver surface recorded under the same conditions. The corresponding difference spectra are shown in fig.4. In spite of application of a different UHV system (see Experimental), the same sample and identical preparation conditions allow us to assign the observed XAS spectra to the nucleophilic (fig.4, curve 1) and electrophilic (fig.4, curves 2) oxygen.

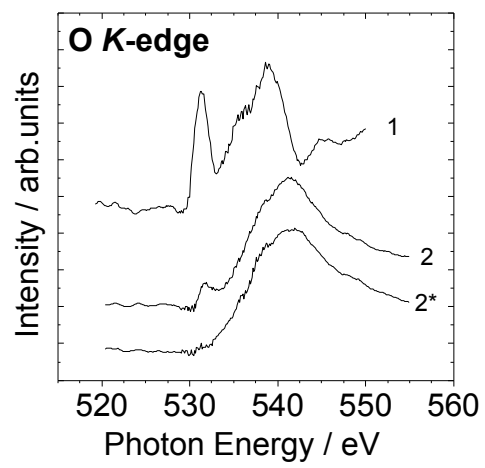

Fig.4. O $K$-edge spectra from polycrystalline silver foil measured during $\mathrm{O}_{2}$ adsorption at $P=10^{-4}$ mbar and $T=470$ $\mathrm{K}$ (1) and after interaction with $\mathrm{C}_{2} \mathrm{H}_{4}+\mathrm{O}_{2}$ reaction mixture for 1 hour at partial pressures of $P\left(\mathrm{C}_{2} \mathrm{H}_{4}\right)=5 \times 10^{-2}$ mbar and $P\left(\mathrm{O}_{2}\right)=2$ mbar, and $\mathrm{T}=470 \mathrm{~K}(2)$. In the latter case, $\mathrm{O} K$ edge spectrum has been recorded also after heating the surface up to $670 \mathrm{~K}$ in $\operatorname{UHV}\left(2^{*}\right)$.

One can see that both the XAS spectra exhibit strong structures up to $20 \mathrm{eV}$ above the threshold, but their shape are quite different. The nucleophilic oxygen gives rise to two signals at photon energies of $\sim 531$ and $\sim 539 \mathrm{eV}$, whereas one broad feature at $541 \mathrm{eV}$ characterizes the electrophilic oxygen. The small signal at $531 \mathrm{eV}$ observed after treatment of silver by the reaction mixture (fig.4, curve 2) seems to arise from the presence of a small amount of the nucleophilic oxygen. This suggestion is based on removal of 
this signal after heating the treated surface up to $570 \mathrm{~K}$ that is in good agreement with desorption temperature of the nucleophilic oxygen [8-17]. The absence of the corresponding signal with $E_{b}(\mathrm{O} 1 \mathrm{~s})=528.2 \mathrm{eV}[12-14,21-23]$ in the XPS spectrum (fig.1a, curve 1) can be explained by fast removal of this highly active oxygen via reaction with hydrocarbon background due to diffusion pumping of the electron spectrometer. In contrast to the XPS spectrometer, the UHV chambers of XAS spectrometer are equipped by turbomolecular pumps which provide hydrocarbon-free residual gases. The assignment of the remaining XAS feature at $541 \mathrm{eV}$ to the electrophilic oxygen is confirmed by its disappearance when the sample is heated up to $770 \mathrm{~K}$. This temperature coincides with the desorption temperature of the electrophilic oxygen [22-23].

The XAS of the electrophilic oxygen (fig.4, curve $2^{*}$ ) provides unambiguous evidence of its atomic origin. One can see that the photon energy range of $530-535 \mathrm{eV}$ typical for $\pi^{*}$ and $\sigma^{*}$ transitions of molecular oxygen [46-47] is absolutely free from any signals (fig.4, curve $2^{*}$ ). Detailed discussion of this and other arguments in the favour of atomic nature of this oxygen species can be found in our previous papers $[23,48]$. A pronounced feature near threshold $(\sim 531 \mathrm{eV})$ in the XAS spectrum of the nucleophilic oxygen, which is generally recognised to be the atomic species arises from the hybridization of oxygen $2 p$ orbitals with silver $4 d$ character $[20,49-50]$. In contrast to this, the signals in the photon energy region of $5-10 \mathrm{eV}$ above threshold has been attributed to oxygen $2 p$ character hybridized with metal 5 sp states $[20,49-50]$.

\section{Discussion}

The set of photoelectron spectroscopy and X-ray absorption data presented in figs.1-4 indicates considerable differences in spectral characteristics of these atomic species. It is clear that detailed analysis of the spectral information for each species and its comparison with literature data are necessary to understand which peculiarities of silver-oxygen bonding are responsible for these differences.

\section{Nucleophilic oxygen}

O1s feature at $528.3 \pm 0.2 \mathrm{eV}$ has been observed many times when bulk silver samples with various silver surfaces was exposed to pure $\mathrm{O}_{2}$ at temperatures above 300 $\mathrm{K}: \operatorname{Ag}(110)$ [12-13] and $\operatorname{Ag}(111)$ [14,17] single crystals, silver foils [26,51] and films [52]. As consequence, the nature of oxygen characterized by this $\mathrm{O} 1 \mathrm{~s}$ feature has been extensively studied by various physical methods [8-17,3136]. It has been shown that regardless of the surface structures, the desorption temperature of this $\mathrm{O}_{\mathrm{ads}}$ is constant. The reported apparent variation of $\mathrm{T}_{\mathrm{des}}$ from 560 to $610 \mathrm{~K}$ [8-17] is most probably due to the details of sample mounting and temperature measurement. The desorption feature together with a pronounced increase in work function (up to $0.8 \mathrm{eV}$ at $\Theta=0.5[8-14]$ ), allowed the authors to describe this species as atomically adsorbed oxide-like oxygen [8-17,31-36]. It has been concluded that the oxidic nature of this species would account for its activity in the nucleophilic attack of $\mathrm{C}-\mathrm{H}$ bond in ethylene [24]. This prompted Grant and Lambert to introduce the term - "nucleophilic oxygen" [2].

Considerable charge transfer from silver to oxygen atoms in the nucleophilic state is also confirmed by the appearance of a ionic component at $367.6 \mathrm{eV}$ in the $\mathrm{Ag} 3 \mathrm{~d}_{5 / 2}$ spectrum (fig.1b, curve 1), with its intensity being proportional to the surface abundance of the nucleophilic oxygen. In the whole range of the coverages (up to half a monolayer) the ratio of the $\mathrm{O} 1 \mathrm{~s}$ signal at $528.3 \mathrm{eV}$ to this $\mathrm{Ag} 3 \mathrm{~d}$ component was close to 0.5 . The negative shift of the $\mathrm{Ag} 3 \mathrm{~d}_{5 / 2}$ binding energy for silver oxides with respect to metallic silver $(368.2 \mathrm{eV})$ is well known [45,53-54] and testifies the formation of positively charged silver ions. The reasons of this unusual shift reported also for a number of other elements ( $\mathrm{Cd}, \mathrm{Cs}, \mathrm{Rb}, \mathrm{Ba}$ [53-54]) originate from the adverse contribution to the negative shift from ground state charge distribution and from final state relaxation processes different for metal and oxide binding states due to different core-hole screening abilities.

Studies of this oxidic oxygen carried out by structural sensitive methods such as LEED or STM [9-14,34$36,55-56$ ] have shown that oxygen atoms in the nucleophilic state agglomerate to some ordered surface structures. Thus, if an $\mathrm{Ag}(110)$ surface is dosed with $\mathrm{O}_{2}$ at $\mathrm{T} \geq 300 \mathrm{~K}$ oxygen atoms cause the formation of one-dimensional oxygen-silver chains. Their density varies with oxygen coverage providing the observation of a series of LEED patterns: from $(7 \times 1)$ to $(2 \times 1)$ at $\Theta=0.5$ [9-11,34-36]. Island formation was concluded by Campbell for $\mathrm{O}_{\text {nucl }}$ on $\operatorname{Ag}(111)$ on the basis that the $p(4 \times 4)$ LEED pattern was observed even with a submonolayer oxygen coverage [14]. The geometry of these islands was observed by STM [56]. The ordered structures may be described structurally as a phase of a surface $\mathrm{Ag}_{2} \mathrm{O}$ oxide. The invariable intrinsic desorption temperature for different silver samples, as well as samll width of the TPD spectrum of the nucleophilic oxygen $(\sim 30-50 \mathrm{~K})$ [10$13,17,23$, fit well to the assignment of a homogeneous surface oxide.

This conclusion makes it possible to use the literature data from bulk silver (I) oxide to discuss the peculiarities of the oxygen-silver interaction of the nucleophilic $\mathrm{O}_{\text {ads }}$. And indeed, the valence band and Auger spectra of bulk $\mathrm{Ag}_{2} \mathrm{O}[19,45]$ are quite similar to those of the nucleophilic oxygen reported in this work. As in our case (fig.2a, curve 1), the UP spectrum of silver oxide consists of two features: at $2-4 \mathrm{eV}$ and at $5-6 \mathrm{eV}$, the ratio of their intensity being dependent on the irradiation used. Taking into account the known energy dependence of the photoionization cross sections of $\mathrm{Ag} 4 \mathrm{~d}$ and $\mathrm{O} 2 \mathrm{p}$ levels, the authors identified these regions as to contain primarily $\mathrm{O} 2 \mathrm{p}$ and $\mathrm{Ag} 4 \mathrm{~d}$ spectral weight, respectively. Such interpretation is in line both with our (fig.2a) and with other literature UPS data [33-36]. The intense signal in the binding energy range of 4-7 eV from the clean surface is assigned to photoelectron emission from silver $4 \mathrm{~d}$ states, whereas the features above the $4 \mathrm{~d}$ band is 
appeared as result of $\mathrm{O}_{2}$ adsorption - to the adsorbed oxygen.

More ambigous is the assignment for the oxygeninduced emission inside the $\mathrm{Ag} 4 \mathrm{~d}$ band $(5-7 \mathrm{eV})$, where the emission from $\mathrm{O} 2 \mathrm{p}$ levels of adsorbed oxygen is quite possible. Such a peak is commonly observed for many metals [57-58], but for Ag it is masked by the intense $4 \mathrm{~d}$ emission. As consequence, the reports about its observation [3336] are rather contradictory. The difference spectra used in this paper allow to observe unambiguously a feature in this binding energy range (fig2b, curve 1). According to Feydt et al [57] who have studied atomic oxygen on W(110), the feature at $\sim 5.7 \mathrm{eV}$ can be assigned to atomic O2p orbital, while the feature above the $\mathrm{Ag} 4 \mathrm{~d}$ band should be due to silver-oxygen hybridized state emission.

The nature of the valence band as a combination of quasi-atomic and hybridized states is very consistent with the fine structure of the $\mathrm{OKL}_{23} \mathrm{~L}_{23}$ spectrum from the nucleophilic oxygen (fig. $3 \mathrm{~b}$, curve 1). The comparison of the data with spectra of atoms with a filled $2 p$ shell such as $\mathrm{Ne}$ or $\mathrm{Mg}[44,59]$ allows us to assign the features at 10.9, 13.8 and $16.2 \mathrm{eV}$ to different two-hole final states denoted as ${ }^{3} \mathrm{P}$, ${ }^{1} \mathrm{D}$ and ${ }^{1} \mathrm{~S}$, respectively, appearing as result of spin-orbit coupling. The additional line at $\sim 6 \mathrm{eV}$ can be attributed to a final state having one hole on oxygen and another on silver [43-44]. It is obvious that the probability of such a process and, hence, the intensity of the related peak, will be increased with the extent of hybridization of oxygen orbitals and the silver band. The same interpretation for this low binding energy feature has been used in the literature [45], where the experimental $\mathrm{OKL}_{23} \mathrm{~L}_{23}$ spectrum of $\mathrm{Ag}_{2} \mathrm{O}$ was compared with the calculated local $\mathrm{O} 2 \mathrm{p}^{4}$ density of states (two-hole approximation). Unfortunately, the relevant integrated Auger data for the nucleophilic oxygen are not available, since electron-excited AES has been used in most papers to characterize it $[8,13-14,34]$.

We conclude that all photoelectron $(\mathrm{O} 1 \mathrm{~s}$ core level, valence band, Auger $\mathrm{OKL}_{23} \mathrm{~L}_{23}$ ) spectra of nucleophilic oxygen are very close to the data characteristic of bulk silver (I) oxide. The same situation is observed for the XANES data which are presented in fig.5a. The comparison of the $\mathrm{O} K$-edge spectrum from the nucleophilic oxygen with the corresponding spectrum of bulk $\mathrm{Ag}_{2} \mathrm{O}$ reveals their close similarity. Both spectra are characterized by two strong signals at different photon energies: near threshold $\sim 531 \mathrm{eV}$ and 3-20 eV above the threshold. The strong signals in the $\mathrm{O}$ $K$-edge spectra indicate that the oxygen-silver interaction is in both cases characterized by a high degree of covalency. Indeed, in a purely ionic model oxygen would exhist the configuration $\mathrm{O} 1 \mathrm{~s}^{2} 2 \mathrm{~s}^{2} 2 \mathrm{p}^{6}$ and the $1 \mathrm{~s} \rightarrow 2 \mathrm{p}$ channel (O Kedge) would be closed for XAS [60]. Covalency reduces the number of filled states with $\mathrm{O} 2 \mathrm{p}$ character so that $\mathrm{O} 2 \mathrm{p}$ derived orbitals become partly unoccupied. This provides the appearance of signals in the $\mathrm{O} K$-edge XAS with their intensity being related to the degree of covalency of the OAg interaction. The other interesting conclusion arising from the XAS data is the hybridization of O2p orbitals with $\mathrm{Ag} 4 \mathrm{~d}$ levels. The XAS signals near threshold are assigned to $\mathrm{O} 2 \mathrm{p}$ hybridization with $4 \mathrm{~d}$ levels of silver [9,49-50]. It should be noted that the participation of Ag4d electrons in bonding of the nucleophilic oxygen with the silver surface explains the photoelectron spectroscopy data, namely the appearance of the ionic component in the $\mathrm{Ag} 3 \mathrm{~d}$ spectrum (fig. $1 \mathrm{~b}$, curve 1) and the separate feature at $\sim 6 \mathrm{eV}$ in the $\mathrm{OKL}_{23} \mathrm{~L}_{23}$ Auger spectra (fig. $3 b$, curve 1).
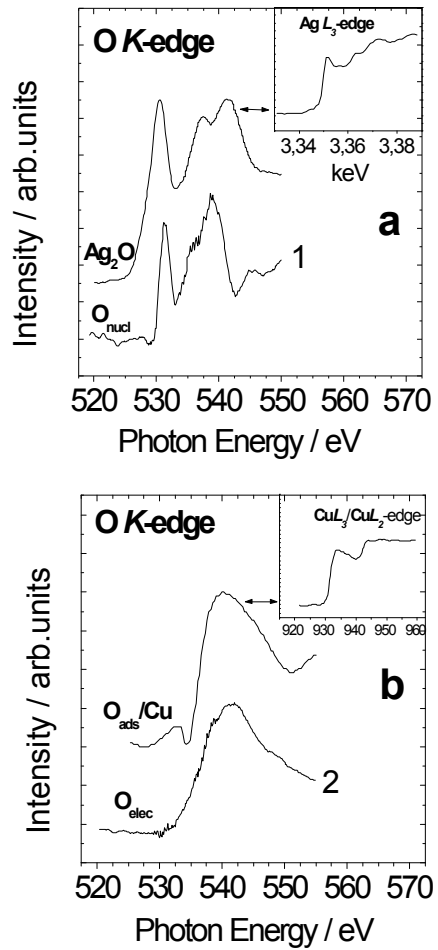

Fig.5. Comparison of the $\mathrm{O} K$-edge spectra of the nucleophilic (1) and electrophilic (2) oxygen with the spectra from bulk silver(I) oxides (a) and from polycrystalline copper foil during the conversion of methanol at catalyst temperature of $600 \mathrm{~K}$ (b). For the reference cases (bulk $\mathrm{Ag}_{2} \mathrm{O}$ and $\mathrm{O}_{\text {sub }} / \mathrm{Cu}$ ) the corresponding Me $L$-edges are also shown as insets.

Unambiguous evidence of participation of $\mathrm{Ag} 4 \mathrm{~d}$ electrons into the formation of the oxygen-silver bonds in bulk $\mathrm{Ag}_{2} \mathrm{O}$ can be found in the papers of Behrens who has monitored $\mathrm{Ag} L_{3}$-edge XAS data for a number of silver compounds and compared them with the spectrum of metallic silver [61-62]. The corresponding spectrum from bulk $\mathrm{Ag}_{2} \mathrm{O}$ taken from [62] is shown in inset of the fig.5a. One can see that this spectrum is characterized by an absorption at about $3.35 \mathrm{keV}$. From previous experimental [61] and theoretical [63] investigations this feature has been attributed to dipole-allowed $2 \mathrm{p}_{3 / 2} \rightarrow 4 \mathrm{~d}$ transitions. The absence of this feature for metallic silver indicates that all $\mathrm{Ag} 4 \mathrm{~d}$ states are occupied in this case. Its appearance for silver (I) oxide has been used by the authors to conclude that Ag4d states are partly depleted. This observation is in contradiction with the rule about non-participating filled sub-shells 
Table 1. Experimental energy shifts $(\mathrm{eV}) \Delta E_{b}(\mathrm{O} 1 \mathrm{~s}), \Delta E_{b}(\mathrm{O} 2 \mathrm{p})$ and $\Delta E_{A}\left(\mathrm{OKL}_{23} \mathrm{~L}_{23}\right)$, and initial $\Delta \varepsilon(\mathrm{O} 1 \mathrm{~s})$ and final $\Delta R$ state contributions in the variation of $\mathrm{O} 1 \mathrm{~s}$ binding energy for different oxygen species on silver.

\begin{tabular}{|c|c|c|c|c|c|c|c|c|c|}
\hline Type of $\mathbf{O}_{\text {ads }}$ & O1s & O2p & OKLL & $\Delta(\mathbf{O 1 s})$ & $\Delta$ (O2p) & $\Delta(\mathbf{O K L L})$ & $2 \Delta(02 p)-\Delta(01 s)$ & $\Delta \mathbf{R}$ & $\Delta \varepsilon$ (01s) \\
\hline Nucleophilic & 528.3 & 1.9 & 514.5 & $\mathbf{0}$ & $\mathbf{0}$ & $\mathbf{0}$ & $\mathbf{0}$ & $\mathbf{0}$ & $\mathbf{0}$ \\
\hline $\begin{array}{c}\text { Electro- } \\
\text { philic }\end{array}$ & 530.4 & 3.3 & 511.9 & 2.1 & 1.4 & -2.6 & 0.7 & -0.9 & -1.2 \\
\hline $\mathrm{Ag}_{2} \mathrm{O}$ & 528.9 & 2 & 513.9 & 0.6 & 0.1 & -0.6 & -0.4 & -0.5 & -0.1 \\
\hline
\end{tabular}

(like the formal $4 \mathrm{~d}^{10}$ configuration of $\mathrm{Ag}^{+}$) in chemical bonding. To explain this contradiction, the authors have suggested that the formation of chemical bonds between oxygen and silver atoms results in partial transfer of electron density from Ag4d to Ag5s orbital [61-62]. In this case the electronic configuration of the silver ions can be described as $4 \mathrm{~d}^{10-\delta} 5 \mathrm{~s}^{\delta}$. Note, this configuration is in good agreement with the structure of the $\mathrm{O} K$-edge XAS spectra both for the nucleophilic oxygen and for the bulk $\mathrm{Ag}_{2} \mathrm{O}$ (fig.5a).

Thus, according to all presented data the nucleophilic oxygen can be described as oxygen incorporated in the structure of surface silver (I) oxide. The oxidic nature of the $\mathrm{Ag}_{2} \mathrm{O}$ surface oxide determines the activity of this oxygen in the nucleophilic breaking of $\mathrm{C}-\mathrm{H}$ bonds that is a first step towards the total oxidation of ethylene. At the same time, the existence of $\mathrm{Ag}^{+}$counter ions has positive influence on selective oxidation as they provide the $\pi$-complexes formation which is a likely intermediate in the ethylene epoxidation reaction [64]. It should be noted that the description of the silver-oxygen bond in this case as purely ionic is not completely correct, as it is in disagreement with the XANES data. The latter demonstrate both $\mathrm{O} 2 \mathrm{p}$ and $\mathrm{Ag} 4 \mathrm{~d}$ orbitals to be partly unfilled due to hybridization. This suggests a considerable degree of covalency in the oxygensilver bond.

\section{Electrophilic oxygen}

The discussion of the nature of the electrophilic oxygen starts with answering the question asked in the Introduction - what peculiarities of oxygen-silver bonding determine so considerable increase in its O1s binding energy compared to the corresponding value for the nucleophilic oxygen (fig.1a). It is pointed out that the reasoning is based on an atomic model, since a molecular nature of the electrophilic oxygen as one of the most possible reasons of its high binding energy value can be fully ruled out by our previous XANES experiments [48].

For the discussion of the differences in valence state of the electrophilic oxygen compared to the oxide-like nucleophilic one, it is useful to estimate the contribution of the relaxation effect to the variation in binding energy [54]. We chose the approach suggesting that the binding energies of the inner and outer shells are affected by relaxation in differing quantitaties. This is confirmed by the O1s binding energy for the electrophilic oxygen that increases by a higher value $(2.1 \mathrm{eV})$ than the $\mathrm{O} 2 \mathrm{p}$ emission $(1.4 \mathrm{eV})$. Hohlneicher et al [39] proposed for an estimation of the relaxation effect contribution $(\Delta \mathrm{R})$ instead of Wagner's equation [37-38]:

$$
\Delta \alpha=\Delta\left[\mathrm{E}_{\mathrm{b}}+\mathrm{E}_{\mathrm{A}}\right]=2 \Delta \mathrm{R},
$$

where $\Delta \alpha$ is the variation of the modified Auger parameter equal to the sum of the kinetic energy of the most prominent Auger line and the binding energy of the XPS line, to use the following relation:

$$
\Delta \beta=\Delta\left[2 \mathrm{E}_{\mathrm{b}}(\mathrm{i})-2 \mathrm{E}_{\mathrm{b}}(\mathrm{k})+\mathrm{E}_{\mathrm{A}}(\mathrm{kii})\right]=2 \Delta \mathrm{R},
$$

which takes into also account the variation of binding energy of outer shell (i) contributing to Auger transition together with core level $(\mathrm{k})$.

$\mathrm{O} 1 \mathrm{~s}$ (fig.1a) and $\mathrm{O} 2 \mathrm{p}$ (fig.2b) binding energies and kinetic energies for $\mathrm{OKL}_{23} \mathrm{~L}_{23}$ Auger transition (fig.3a) are collected in Table 1 together with the calculated shifts of energies determined with respect to characteristics of the nucleophilic oxygen. From the measured energy shifts we calculated $\Delta \mathrm{R}$ and, finally, the 'true' variation of orbital energy $(\Delta \varepsilon)$ according to:

$$
\Delta \varepsilon=-\left[\Delta \mathrm{E}_{\mathrm{b}}+\Delta \mathrm{R}\right]
$$

Table 1 further contains the parameters for bulk silver (I) oxide. The original values of the $\mathrm{Ag}_{2} \mathrm{O}$ energies have been taken from [45].

One can see that the shift of O1s binding energy for bulk $\mathrm{Ag}_{2} \mathrm{O}$ compared to the value for the nucleophilic oxygen $(0.6 \mathrm{eV})$ is determined essentially by the relaxation contribution. The subtraction of the relaxation shift from the total variation of O1s binding energy leads to a very small difference $(0.1 \mathrm{eV})$ in orbital energy of the nucleophilic oxygen and oxygen in the structure of bulk $\operatorname{Ag}_{2} \mathrm{O}$. This is a strong additional confirmation of the chemical similarity of the oxygen-silver interaction in two twodimensial and three-dimensial silver oxides. The more effective compensation of the core hole remaining after emission of a O1s electron from the nucleophilic oxygen can be explained by the direct contact of a surface oxide with the metallic silver. Enhancing extraatomic relaxation due to 
electron transfer from the electron gas of the underlying metal.

The contribution of the final state relaxation effect to the variation of the $\mathrm{O} 1 \mathrm{~s}$ binding energy is also rather considerable for the electrophilic oxygen (table 1). Approximately half of the shift of $\mathrm{E}_{b}(\mathrm{O} 1 \mathrm{~s})$ between the $\mathrm{O}_{\text {elec }}$ and the $\mathrm{O}_{\text {nucl }}$ originates from the relaxation and only half of the shift is determined by the initial state effect, i.e. by the changes in the electron configuration of oxygen atoms. The increase of orbital energy for a negatively charged ion means the decrease of the charge [54] at electrophilic oxygen.

Additional confirmation of a considerable decrease in the charge on the electrophilic oxygen originates from the analysis of the Auger spectra. The advantage of this approach dealing with the structure of the whole OKLL Auger group (fig.3a) consists in an insignificant contribution of the relaxation effect to the experimental data monitored in the same experiment. Wagner et al [41] have emphasized that the spacing between the $\mathrm{OKL}_{23} \mathrm{~L}_{1}$ and the dominant $\mathrm{OKL}_{23} \mathrm{~L}_{23}$ Auger structure is variable between about $20 \mathrm{eV}$ and $25 \mathrm{eV}$ for a number of oxides, hydroxides, salts, etc. The authors have shown that the increase in the line separation arises from a decrease in ionic character of the oxygen-metal bond. At the same time, Weißmann [40] have shown that intensity ratios of the $\mathrm{OKL}_{23} \mathrm{~L}_{23}$ and $\mathrm{OKL}_{1} \mathrm{~L}_{1}$ Auger lines are correlated quantitatively with the atomic charges on oxygen calculated on the basis of Pauling's scale of electronegativity. A detailed analysis of both parameters of the OKLL Auger group can be found in the paper of Ascarelli and Moretti [42] who have revealed a good correlation between the separation of the $\mathrm{OKL}_{23} \mathrm{~L}_{23} / \mathrm{OKL}_{23} \mathrm{~L}_{1}$ oxygen lines and their relative intensities. This correlation together with the points for the nucleophilic and electrophilic oxygen can be seen in the fig.6a. One can see that our experimental data are in good agreement with the correlation from literature indicating a significant variation of the ionicity in the silveroxygen interaction for the oxygen species studied. To make quantitative estimation of this variation we have juxtaposed the $E_{\text {kin }}\left(\mathrm{OKL}_{23} \mathrm{~L}_{23}\right)-\mathrm{E}_{\text {kin }}\left(\mathrm{OKL}_{23} \mathrm{~L}_{1}\right)$ values for the nucleophilic and electrophilic oxygen (fig.5b) with the dependence taken from [42] connecting of the Auger line separation with the atomic charge on the oxygen calculated using Pauling's electronegativity scale as reported in literature [65]. One can see that in good agreement with the $\mathrm{O} 1 \mathrm{~s}$ orbital energy variation (table 1 ) the atomic charge on the electrophilic oxygen is by $\sim 1.3$ units lower than that on the nucleophilic $\mathrm{O}_{\text {ads }}$. The deviation of the value for oxygen charge $(\sim 1.65)$ in the nucleophilic species from 2 - indicates hole states in the $\mathrm{O} 2 \mathrm{p}$-derived bands that have been also concluded from XANES data (figs.4 and 5a).

The decrease of the electron density at oxygen atoms in the electrophilic state should originate from a different bonding of oxygen with the silver surface. This general conclusion is confirmed by XANES data. Indeed, the $\mathrm{O}$ $K$-edge XAS data of the electrophilic oxygen do not exhibit absorption near threshold $(530-532 \mathrm{eV})$ which is clearly present for the nucleophilic oxygen. This fact indicate that
Ag4d electrons do not participate in the bonding of the electrophilic oxygen with the silver surface. This conclusion is in accordance with the absence both of the ionic components in the Ag3d spectra (fig.1b, curve 2) and of a low binding energy peak in the $\mathrm{OKL}_{23} \mathrm{~L}_{23}$ spectrum (fig. $3 \mathrm{~b}$, curve 2) measured from the Ag surface with the electrophilic oxygen.
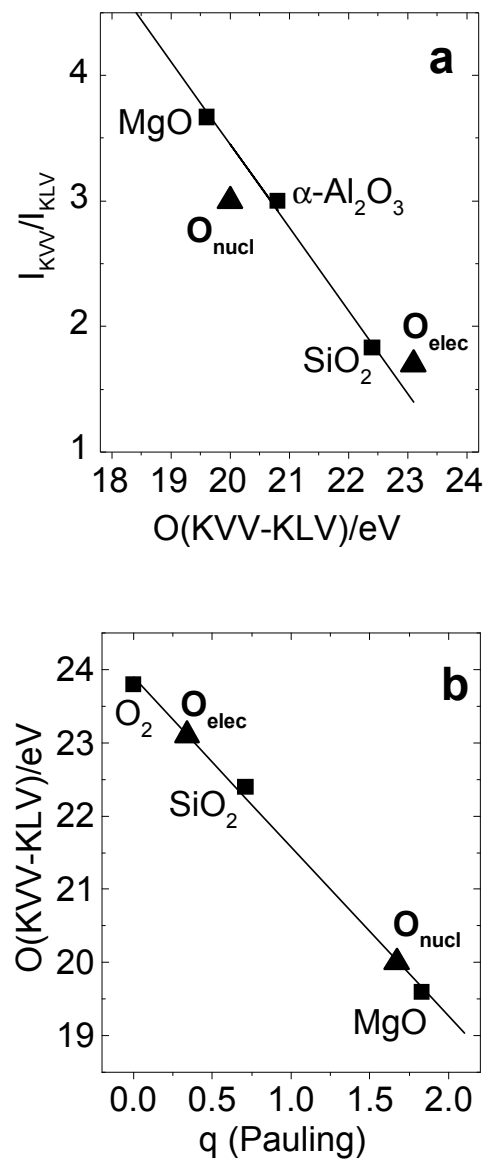

Fig.6. Relationships of the spacing of the $\mathrm{OKL}_{23} \mathrm{~L}_{1}$ and $\mathrm{OKL}_{23} \mathrm{~L}_{23}$ Auger lines with their relative intensities (a) and atomic charge on the oxygen calculated using Pauling's electronegativity scale (b) for the oxygen species on the silver surface (fig. $3 b$ ) and for a number of binary oxides [67].

A similar $\mathrm{O} K$-edge spectrum as presented here was revealed in recent papers [66-67] devoted to an in-situ XAS study of selective oxidation of methanol over copper. The corresponding spectrum recorded at $600 \mathrm{~K}$ is presented in the fig. $5 \mathrm{~b}$. On the basis of these data the formation of a suboxide has been concluded. Good agreement with the $\mathrm{O}$ $K$-edge spectrum of the electrophilic oxygen indicates the same type of bonding interaction between of oxygen and both metals. The copper $L_{2,3}$-edge spectrum recorded simultaneously (fig.5b, inset) exhibits an absorption step structure typical of a metal. The absence of any white line indicates that $\mathrm{Cu} 3 \mathrm{~d}$ electrons are hardly involved in the formation of the oxygen-metal bond. Assuming a similar bonding in the oxygen-silver system (fig.4b) the same conclusion about the participation of only $5 \mathrm{sp}$ states of silver in chemical bonding can be made for the electrophilic oxygen. 
Thus, both photoelectron spectroscopy and X-ray absorption data allow us to represent the electrophilic oxygen as an atomic oxygen adsorbed on the surface of metallic silver with less exchange of electron density between metal and oxygen than characteristic of the oxide-like nucleophilic $\mathrm{O}_{\text {ads }}$. Only Ag5sp levels participate in the oxygen-silver interaction for the electrophilic oxygen. The low electron charge on the electrophilic oxygen explains its selectivity towards interaction with the double $\mathrm{C}=\mathrm{C}$ bond of ethylene leading to the formation of ethylene oxide.

\section{Adsorption models for the oxygen species}

Further understanding of the nature of the nucleophilic and electrophilic oxygen is impossible without consideration of possible models of adsorption centers that should be followed by theoretical representations of their energetic and spectroscopic characteristics. This will help in the explanation of the uniqueness of silver as heterogeneous catalysts for ethylene epoxidation.

The similarity of spectroscopic characteristics of the nucleophilic oxygen to those of bulk silver (I) oxide suggests a similarity of their structural motives. The lattice structure of bulk $\mathrm{Ag}_{2} \mathrm{O}$ consists of a linear coordination of Ag-O-Ag fragments. Namely linear coordination of the $\mathrm{Ag}^{+}$ cations has been suggested [62] to be preferable for hybridization of $\mathrm{Ag}_{4} \mathrm{~d}_{\mathrm{z}}{ }^{2}$ and $5 \mathrm{~s}$ orbitals leading to a valence electron distribution that can be rationalized as $4 \mathrm{~d}^{10-\delta} 5 \mathrm{~s}^{\delta}$. A coordination close to linear has been concluded for $(2 \times 1)$-O structure on $\operatorname{Ag}(110)$ surface on the basis of STM [55] and photoelectron diffraction [68] data. It should be reminded that the $(2 \times 1)-O$ adlayer exhibits the same photoemission characteristics as the nucleophilic oxygen. Taking into account all these arguments, we can conclude that adsorption complex for the $\mathrm{O}_{\text {nucl }}$ should exhibit a linear coordination and may be approximated by the structure of added rows as in the case of the oxygen adsorbed on $\operatorname{Ag}(110)$ single crystal surfaces. Quantum chemical calculations of energetic characteristics of various oxygen adsorbed on $\mathrm{Ag}(110)$ [69] have shown the participation of the $\mathrm{Ag} 4 \mathrm{~d}$ orbitals in oxygen-silver bonding in the case of the $(2 \times 1)-\mathrm{O}$ structure.

A more complex situation is observed for the electrophilic oxygen. On one hand, being a purely adsorbed species it can not be related to any bulk silver oxide. On the other hand, all studies which reported the O1s feature at $530.5 \mathrm{eV}$ either did not characterize it by structure-sensitive methods, or assigned this signal to other species (carbonates, subsurface oxygen, etc.). Our recent paper in which $\mathrm{O}_{2}$ adsorption on $\operatorname{Ag}(111)$ in the temperature range of $300-500$ $\mathrm{K}$ has been studied using angular-dependent XPS [17] is the first step in this direction. It has been shown that the atomically adsorbed oxygen with $\mathrm{E}_{\mathrm{b}}(\mathrm{O} 1 \mathrm{~s})=530.5 \mathrm{eV}$ produced as result of room temperature adsorption is evidently located at the surface. Quantum chemical considerations published in [70] allow to attribute this species to oxygen adsorbed in a three-fold position above an octahedral void of the silver lattice. It has been shown that this adsorption position is most favorable energetically. When the crystal temperature is raised from $300 \mathrm{~K}$ to $420 \mathrm{~K}$ this oxygen incorporates into silver [17] and reconstructs the uppermost silver layer. The reconstruction is accompanied by a shift of the O1s spectrum from $530.0 \mathrm{eV}$ to $528.2 \mathrm{eV}$. This scheme of the surface transformations has been confirmed in recent STM investigation [56].

The agreement in the binding energies of the surfaceadsorbed oxygen and the electrophilic oxygen suggests the similarity of their local structure. However, further analysis of the electrophilic oxygen is impossible without its characterization by structural methods. From the quantum chemical investigation [70] it follows that only $\mathrm{Ag} 5 \mathrm{~s}$ electrons participate in the oxygen-silver bonding when a three-fold hollow site is the location of the adsorbate. This observation is in line with all experimental data.

\section{Summary}

Exposure of clean silver to $\mathrm{O}_{2}$ at $\mathrm{P}=10^{-4} \mathrm{mbar}$ and $\mathrm{T}=470 \mathrm{~K}$ produces atomically adsorbed oxygen with $\mathrm{E}_{\mathrm{b}}(\mathrm{O} 1 \mathrm{~s})=528.3 \mathrm{eV}$ denoted as the nucleophilic species. A stoichiometry of $\operatorname{Ag}_{(\mathrm{x}=2 \pm 0.2)} \mathrm{O}$, a ionic component in the $\mathrm{Ag} 3 \mathrm{~d}_{5 / 2}$ spectrum at $367.7 \mathrm{eV}$ allow to conclude the formation of a surface silver (I) oxide that is confirmed by the similarity of its spectral characteristics with those of bulk $\mathrm{Ag}_{2} \mathrm{O}$. The oxidic nature of the oxygen-silver bond explains both its particiation in the total oxidation route and the promotion of ethylene adsorpion due to formation of $\pi$ complexes with positively charged silver ions. In spite of considerable charge transfer from silver to oxygen typical of binary metal oxides, covalency of the oxygen-silver interaction due to hybridization of $\mathrm{O} 2 \mathrm{p}$ orbitals not only with $5 \mathrm{~s}$ state, but also with formally filled $4 \mathrm{~d}$ levels of silver is indicated by the XAS spectra shape. All spectral parameters suggest a linear coordination of $\mathrm{Ag}-\mathrm{O}-\mathrm{Ag}$ fragments as structure motif.

The treatment of clean silver with $\mathrm{C}_{2} \mathrm{H}_{4}(2.5 \%)+$ $\mathrm{O}_{2}$ at $\mathrm{P}=2$ mbar and $\mathrm{T}=470 \mathrm{~K}$ leads to another type of atomic adsorbed oxygen with $\mathrm{E}_{\mathrm{b}}(\mathrm{O} 1 \mathrm{~s})=530.4 \mathrm{eV}$. As shown earlier, this species named as electrophilic oxygen is responsible for the epoxidation route. The estimation of the relaxation contribution in total shift of its $\mathrm{O} 1 \mathrm{~s}$ spectrum with respect to the nucleophilic oxygen ospecies reveals that about half of the shift can be explained by a final state effect. The remaining shift originates from a change in orbital energy. The observed shift of the orbital energy to higher values indicates a decrease of the electron density at the electrophilic oxygen atoms. The same conclusion follow from the Auger data which show a higher value for the $\mathrm{OKL}_{23} \mathrm{~L}_{23}$ and $\mathrm{OKL}_{23} \mathrm{~L}_{1}$ lines separation and a lower ratio of their intensities in the case of the electrophilic oxygen compared to the nucleophilic one. The absence of signals at 530 $-535 \mathrm{eV}$ photon energy in the $\mathrm{O} K$-edge spectrum of the electrophilic oxygen clearly indicate that $\mathrm{Ag} 4 \mathrm{~d}$ electrons do not participate in oxygen-silver bonding in this case.

This detailed spectroscopic analysis was only possible due to high pressure high-temperature preparation of the oxygen species and in-situ observation. A clear corre- 
lation of electronic structure and catalytic function was derived if the earlier in-situ study [48] is combined with the present results. The still missing exact geometric structures of the two catalytically relevant surface species may be a challenge to theoretical studies using the spectral information of the present study as reference.

\section{Acknowledgements}

This work was supported in part by Russian Foundation for Basic Research, grant No. 00-15-99335. The authors would like to thank BESSY staff for the help in carrying out the XAS experiments. Furthermore, V.I.B. gratefully acknowledges the Max-Planck-Gesselschaft for financial support of his visit to FHI and work at BESSY.

\section{References}

1. C.T. Campbell and M.T. Paffett, Surf. Sci., 1984, 139, 396.

2. R.B. Grant and R.M. Lambert, J. Catal., 1985, 92, 364.

3. R.A. van Santen and C.P.M. de Groot, J. Catal., 1986, 98, 364.

4. R.A. van Santen and H.P.C.E. Kuipers, Adv. Catal., 1987, 35, 26.

5. M.A. Barteu and R.J. Madix, in: The Chemical Physics of Solid Surfaces and Heterogeneous Catalysis, Vol. 4, Eds. D.A. King and D.P. Woodruff (Elsevier, Amsterdam, 1982), chapter 4.

6. S. Hawker, C. Mukoid, J.P.S. Badyal and R.M. Lambert, Surf. Sci., 1989, 219, L615.

7. A.J. Nagy, G. Mestl and R. Schlogl, J. Catal., 1999, 188, 58.

8. G. Rovida, F. Pratesi, M. Maglietta and F. Ferroni, Surf. Sci., 1974, 43, 230.

9. G. Rovida and F. Pratesi, Surf. Sci., 1975, 52, 542.

10. C. Backx, C.P.M. de Groot, R. Biloen and W.M.H. Sachtler, Surf. Sci., 1981, 104, 300.

11. C. Backx, C.P.M. de Groot, P. Biloen and W.M.H. Sachtler, Surf. Sci., 1983, 128, 81.

12. M. A. Barteau and R. J. Madix, J. Electron Spectrosc. Relat. Phenom., 1983, 31, 101.

13. C.T. Campbell and M.T. Paffett, Surf. Sci., 1984, 143, 517.

14. C.T. Campbell, Surf. Sci., 1985, 157, 43.

15. C.T. Campbell, Surf. Sci., 1986, 173, L641.

16. R.B. Grant and R.M. Lambert, Surf. Sci., 1984, 146, 256.

17. V.I. Bukhtiyarov, V.V. Kaichev and I.P. Prosvirin, J. Chem. Phys., 1999, 111, 2169.

18. P.J. van Hoek, E.J. Baerends and R.A. van Santen, J. Phys. Chem., 1989, 93, 6469.

19. X. Bao, M. Muhler, Th. Shedel-Niedrig and R. Schlögl, Phys. Rev. B, 1996, 54, 2249.

20. Th. Shedel-Niedrig, X. Bao, M. Muhler and R. Schlögl, Ber. Bunsengen. Phys. Chem., 1997, $101,994$.

21. V.I. Bukhtiyarov, A.I.Boronin, I.P. Prosvirin and V.I. Savchenko, J. Catal., 1994, 150, 262.

22. V.I. Bukhtiyarov, I.P. Prosvirin and R.I. Kvon, Surf. Sci., 1994, 320, L47.

23. V.I. Bukhtiyarov, V.V. Kaichev, I.P. Prosvirin and E.A. Podgornov, Catal. Lett., 1999, 57, 233.

24. R.A. van Santen, S. Moolhuysen and W.M.H. Sachtler, J. Catal., 1980, 65, 478.

25. R.W. Joyner, M.W. Roberts and K. Yates, Surf. Sci., 1979, 87, 501.

26. A.I. Boronin, V.I. Bukhtiyarov, A.L. Vishnevskii, G.K. Boreskov, V.I. Savchenko, Surf. Sci., 1988, $201,195$.

27. A. Knop-Gericke, M. Hävecker and Th. Shedel-Niedrig, Nucl. Instrum. Meth. Phys. Resear. A, 1998, $406,311$.

28. L. Lefferts, J.G. van Ommen and J.R.H. Ross, J. Chem. Soc. Faraday Trans. I, 1987, 83, 161.

29. C. Rehren, M. Muhler, X. Bao, R.Schlögl and G.Ertl, Z. Phys. Chem., 1991, 11, 174.

30. D.L. Adams and J.N. Andersen, FitXPS v., ftp://boopic.dfi.aau/dk/pub/fitxps

31. M.A. Barteau and R.J. Madix, Surf. Sci., 1984, 140, 108.

32. A.F. Carley, P.R. Davies, M.W. Roberts and K.K. Thomas, Surf. Sci., 1990, 238, L467.

33. I.E. Wachs and S.R. Kelemen, J. Catal., 1981, 71, 78.

34. K.C. Prince and A.M. Bradshaw, Surf. Sci., 1983, 126, 49.

35. K.C. Prince, G. Paolucci and A.M. Bradshaw, Surf. Sci., 1986, 175, 101.

36. D. Sekiba, H. Nakamizo, R. Ozawa, Y. Gunji and H. Fukutani, Surf. Sci., 2000, 449, 111.

37. C.D. Wagner, Faraday Discuss. Chem. Soc., 1975, 60, 291.

38. C.D. Wagner, J. Electron Spectrosc. Relat. Phenom., 1977, 10, 305.

39. G. Hohlneicher, H. Palm and H.-J. Freund, J. Electron Spectrosc. Relat. Phenom., 1985, 37, 209.

40. R. Weißmann, Solid State Commun., 1979, 31, 347.

41. C.D. Wagner, D.A. Zlatko and R.H. Raymond, Anal. Chem., 1980, 52, 1445.

42. P. Ascarelli and G. Moretti, Surf. Interf. Anal., 1985, 7, 8.

43. P.H. Citrin, J.E. Rowe and S.B. Christman, Phys. Rev. B, 1976, 14, 2642.

44. J.C. Fuggle, E. Umbach, R. Kakoschke and D. Menzel, J. Electron Spectrosc. Relat. Phenom., 1982, $26,111$.

45. L.H. Tjeng, M.B.J. Meinders, J. van Elp, G.A. Sawatzky and R.L. Johnson, Phys. Rev. B, 1990, 41, 3190.

46. R.J. Guest, B. Hernäs, P. Bennich, O. Björneholm, A. Nilsson, R.E. Palmer and N. Mårtensson, Surf. Sci., 1992, 278, 239.

47. J. Pawela-Crew, R.J. Madix and J. Stöhr, Surf. Sci., 1995, 339, 23.

48. V.I. Bukhtiyarov, M. Hävecker, V.V. Kaichev, A. Knop-Gericke, R. Mayer and R. Schlögl, Catal. Lett., $2000,74,121$.

49. F.M.F. de Groot, M. Grioni, J.C. Fuggle, J. Ghijsen and G.A. Sawatzky, H. Petersen, Phys. Rev. B, $1989,40,5715$.

50. J. Purans, A. Kuzmin, Ph. Parent and C. Laffon, Physica B, 1999, 259-261, 1157. 
51. R.W. Joyner and M.W. Roberts, Chem. Phys. Lett. 60, 459 (1979).

52. A.I. Boronin, V.I. Bukhtiyarov, A.L. Vishnevskii, G.K. Boreskov and V.I. Savchenko, Kinetika i kataliz, 1984, 25, 1508 (in Russian).

53. J.S. Hammond, S.W. Gaarenstroom and N. Winograd, Anal. Chem., 1975, 47, 2193.

54. J.F. Moulder, W.F. Stickle, P.E. Sobol and K.D.Bomben, in: J. Chastain (Ed.), Handbook of X-ray Photoelectron Spectroscopy, Perkin Elmer, Eden Praine, 1992.

55. M. Taniguchi, K. Tanaka, T. Hashizume and T. Sakurai, Surf. Sci., 1992, 262, L123.

56. C.I. Carlisle, T. Fujimoto, W.S. Sim and D.A. King, Surf. Sci., 2000, 470, 15.

57. J. Feydt, A. Elbe, H. Engelhard, G. Meister and A. Goldmann, Surf. Sci., 1999, 440, 213.

58. C.Q. Sun and S. Li, Surf. Rev. Lett., 2000, 7, 213.

59. H. Körber and W. Mehlhorn, Z. Phys., 1966, 191, 217.

60. J. Stöhr, in: R. Gomer (Ed.) NEXAFS Spectroscopy, Springer Series in Surface Sciences, vol. 25, (Springer, Heidelberg, 1992).

61. P. Behrens, Solid State Commun., 1992, 81, 235

62. P. Behrens, S. Aßmann, U. Bilow, C. Linke and M. Jansen, Z. Anorg. Allg. Chem., 1999, 625, 111.

63. M.T. Czyzyk, R.A. de Groot, G. Dalba, P. Fornasini, A. Kisiel, F. Rocca and E. Burattini, Phys. Rev. B, 1989, $39,9831$.

64. D.A. Bulushev, E.A. Paukshtis, Y.N. Nogin and B.S. Balzhinimaev, Appl. Catal. A, 1995, 123, 301.

65. L.E. Orgel, J. Chem. Phys., 1958, 4186.

66. M. Hävecker, A. Knop-Gericke, Th. Shedel-Niedrig and R Schlögl, Angew. Chem. Int. Ed., 1998, 37, 1939.

67. M. Hävecker, A. Knop-Gericke, Th. Shedel-Niedrig and R Schlögl, Topics Catal.,. 2001, $15,27$.

68. M. Pascal, C.L.A. Lamont, P. Baumgartel, R. Terborg, J.T. Hoeft, O. Schaff, M. Polcik, A.M. Bradshaw, R.L. Toomes and D.P. Woodruff, Surf. Sci., 2000, 464, 83.

69. I.L. Zilberberg and G.M. Zhidomirov, J. Struct. Chem., 1997, 38, 528.

70. I.L. Zilberberg, M.A. Milov and G.M. Zhidomirov, J. Struct. Chem., 1999, 40, 350. 